\title{
A model for triggering mechanisms of shallow landslides
}

\author{
L. Montrasio and R. Valentino \\ Department of Civil Engineering, University of Parma, Italy
}

Received: 8 January 2008 - Revised: 7 August 2008 - Accepted: 29 August 2008 - Published: 21 October 2008

\begin{abstract}
Rainfall-induced shallow landslides, also called "soil slips", are becoming ever more frequent all over the world and are receiving a rising interest in consequence of the heavy damage they produce. At the University of Parma, a simplified physically based model has been recently set up for the evaluation of the safety factor of slopes which are potentially at risk of a soil slip. This model, based on the limit equilibrium method applied to an infinite slope, takes into account some simplified hypotheses on the water down-flow and defines a direct correlation between the safety factor of the slope and the rainfall depth. In this paper, this model is explained in detail and is used in a back analysis process to verify its capability to foresee the triggering instant of rainfall-induced shallow landslides for some recent case studies in the Emilia Romagna Apennines (Northern Italy). The results of the analyses and of the model implementation are finally shown.
\end{abstract}

\section{Introduction}

The literature and various studies performed on shallow landslides or "soil slips" reveal that they have caused heavy damage in different environmental conditions all over the world (Kesseli, 1943; Campbell, 1975; Govi and Sorzana, 1980; Govi and Mortara, 1981; Sidle and Swanston, 1982; Ellen and Wieczorek, 1988). Important contributions on the matter, referring to the Italian territory, are the data collection carried out by the Piedmont Region after the 1994 flood (Sutera Sardo et al., 1996; Campus et al., 1998) and the scientific notes, concerning similar types of events, in other regions: Campania in 1998 (Cascini et al., 2000, 2003; Olivares 2001; Olivares and Picarelli, 2001), Umbria in 2004 (Cardinali et al., 2006), Tuscany in 1996 (Delmonaco et al., 2003) and Emilia Romagna in 2000 (Emilia Romagna Re-

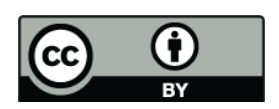

Correspondence to: L. Montrasio (lorella.montrasio@unipr.it) gion, Report 2002). Soil slips are portions of soil of small thickness that, in consequence of rainfalls, detach from the shallow part of a slope and move in different ways. A typical soil slip can be characterised by a first triggering phase and a second evolving phase that may appear as a global translational movement of a few centimetres (Fig. 1A) or several meters (Fig. 1B) or it may turn into a much more evident phenomenon having the characteristics of a mud slick (Fig. 1C and D). In the last case, the speed of the movement can reach $9 \mathrm{~m} \mathrm{~s}^{-1}$. Figure 2 shows a typical example of a soil slip which occurred in Piedmont in 1994.

Such movements mainly occur in slopes characterised by a substratum of varied nature and a stratum of topsoil of small thickness (1-2.5 m max).

The main causes of this phenomenon seem to be prolonged rainfalls of medium intensity or very intense rainfalls following relatively wet periods.

For the time being, the models that can be used to foresee the triggering mechanisms present particularities and limits that make their use suitable for different needs. These approaches can be roughly distinguished into numerical and simplified methods. Numerical methods (FEM, BE, FD), which allow a three-dimensional study of the problem considering complex constitutive models for the soil (elastoplastic with isotropic or anisotropic hardening), partial saturation and steady-state seepage in saturated and unsaturated soil as well as possible heterogeneity, lead to fairly accurate solutions. Nevertheless, the computational load, especially in the case of accurate modelling of a large number of aspects involved in the problem, is high and the difficulty in determining the values of the parameters increases progressively with their number. Moreover, the parameters do not always have a clear and direct relation with any physical aspect and can often be determined only through non-standard geotechnical tests. In addition, the models that accurately describe the groundwater seepage as the main cause of a slope instability (Hodge and Freeze, 1997; Rulon and Freeze, 1985; Clarizia et al., 1996) need the use of rather sophisticated and time consuming numerical codes.

Published by Copernicus Publications on behalf of the European Geosciences Union. 


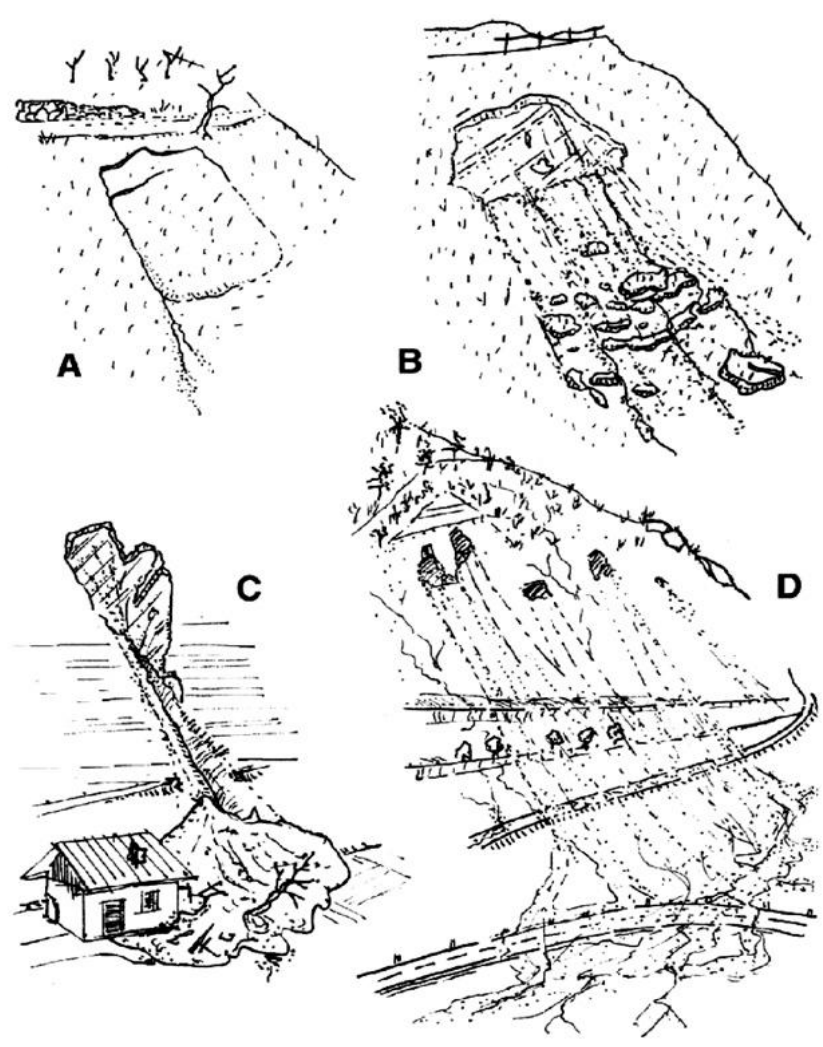

Fig. 1. Illustration of four different kinds of soil slip (Campus et al., 1998).

If the aim of the study is the evaluation of the safety factor of a single slope or the design of stabilising systems, the use of such models is very helpful, since the accuracy of the result is important for reaching the desired objective.

If, on the other hand, the aim of the study is the understanding of the main factors determining the susceptibility of a slope or of a class of slopes in a certain territory, in order to set up a warning system for the population in areas where the phenomena may occur, then the use of "complex" methods could be ineffective for reaching the goal of the study. From this viewpoint, "simplified" methods capable of a qualitative description of the phenomena may be advantageous.

Two different types of simplified methods may be distinguished: the "black box" and the "rational" methods (Valentino, 1999; Cascini et al., 2005). The first method is aimed at foreseeing the main factors causing the occurrence of the phenomena and, in particular, the critical rainfall amount triggering the soil slip (Govi et al., 1985; Versace et al., 2002). This method often neglects the mechanical behaviour of the soil. The second method, tends to consider, even if in a simplified way, the role played by the soil, in foreseeing the occurrence of a soil slip both on small and large scales. These kinds of models, which can be considered deterministic, take into account not only external factors, such

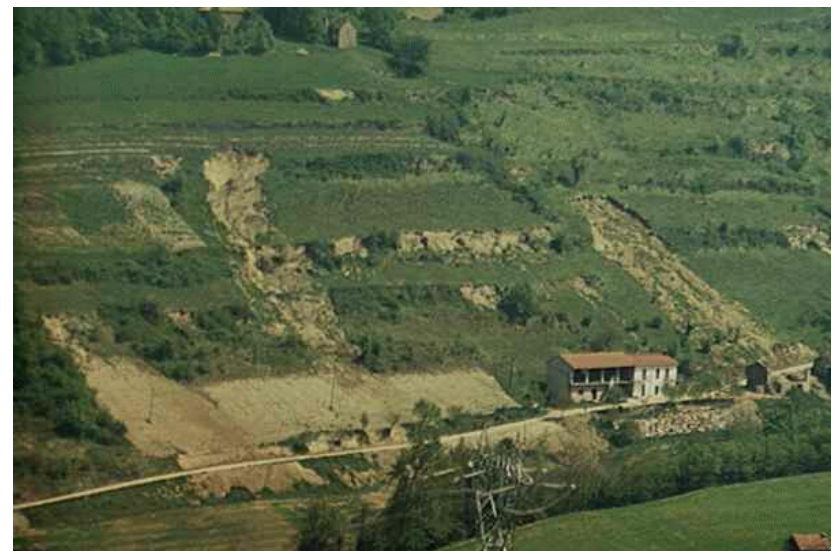

Fig. 2. Soil slip occurred in Piedmont Region in November 1994 (from CNR-IRPI).

as the rainfall amount, but also the geometrical features of the slope, the physical and mechanical behaviour of the soil and the mechanism of rainfall infiltration (Haefeli, 1948; Campbell, 1975; Montgomery and Dietrich, 1994; Bandis, 1996; Alonso et al., 1995; Delmonaco et al., 2003; Iverson and Major, 1987; Iverson, 2000; Salciarini et al., 2006).

The model, which will be described in detail in the following paragraphs and which has been the topic of other recent papers (Montrasio, 2000; Montrasio et al., 2002; Montrasio and Valentino, 2007), may be considered a simplified method of analysis aimed at highlighting the main aspects of the triggering phenomenon, taking into account the soil features, without introducing a large number of parameters. Moreover, through a simplified water-flow model, this method allows to relate directly the safety factor of a slope with the rainfall amount and can thus be easily extended to a regional scale.

Finally, in this paper the above discussed model is used to verify its capability to foresee the occurrence of the phenomenon in four recent case studies in the Emilia Romagna Apennines (Northern Italy), on the basis of known slope geometrical features, the geotechnical characterisation and the shear strength of the soils involved, the drainage capability of the slope and the way of rainfall infiltration.

\section{The simplified model}

\subsection{Considerations on the physical phenomenon}

The theoretical modelling of the problem is based on:

- the analysis and comprehension of the physical phenomenon;

- the formulation of assumptions on the main factors that govern the problem;

- the use of simplified methods of analysis. 
The model presented is based on the hypotheses derived from the analysis of a large number of sites where real events occurred during the 1994 Piedmont flood. The principal aspects are taken into account in the model in order to reach the goals discussed in the introduction. The hypotheses are the following:

a) The portion of the soil subject to sliding is generally characterised by certain heterogeneity and by the presence of a large number of soil pipes (caused, for example, by the activity of various living organisms). This fact is also confirmed by studies carried out by agronomists (Bouma and Dekker, 1978; Bouma, 1981, 1991). This leads to the impossibility of considering the top-soil as a continuum, as typically done in soil mechanics.

b) The top-soil is partially saturated but the water content increases with depth.

c) The sliding surface does not coincide with the contact between the soil and the bedrock but is dislocated into the superficial portion of the soil.

d) The geometrical medium characteristics are: the medium slope angle is much greater than the soil shear strength angle (slope angle equal to $48^{\circ}$ versus shear strength angle equal to $27^{\circ}$ ) (Campus et al., 1998) and the soil is mostly normally consolidated.

These considerations, together with some field studies of rainfall infiltration into unsaturated soils (Zhan et al., 2007), were instrumental to derive the following hypotheses on the triggering mechanisms:

- the slope is initially stable, due to the partial saturation of the soil, which contributes to its shear strength;

- the water can flow vertically and very easily through the macro-pores and reach the deeper parts of the channels, where it starts to flow in different directions through the micro-pores of the soil matrix;

- starting from the zones around macro-pores, the infiltration through the micro-pores causes the saturation of the surrounding soil (Fig. 3a);

- if the rain does not stop, the process continues, and greater and greater portions of soil become saturated (Fig. 3b). In this phase, the stability is guaranteed by the fact that the portions of soil, which are saturated (and which have reached the failure condition), are not continuous inside the partially saturated mass. If the raining process persists, the saturated portions of soil extend and become continuous, leading to the loss of partial saturation in most of the soil (Fig. 3c), until stability cannot be maintained. The sliding process starts when a relatively wide continuous stratum of saturated soil has formed and the subsequent evolution of sliding can be more or less catastrophic, depending on the thickness of this saturated stratum. If this stratum is thin, the collapse may consist only

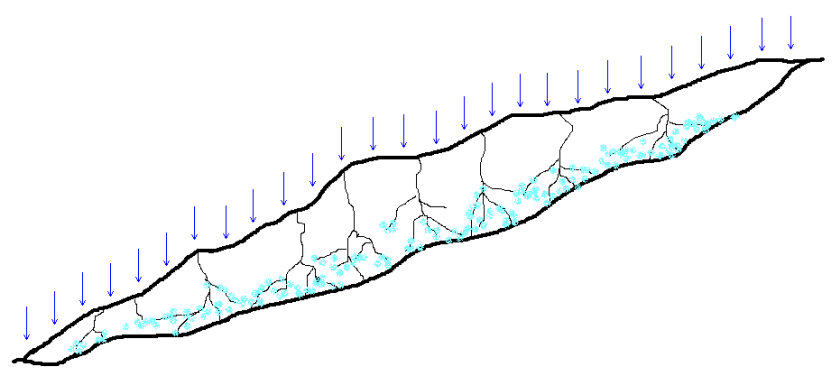

(a)

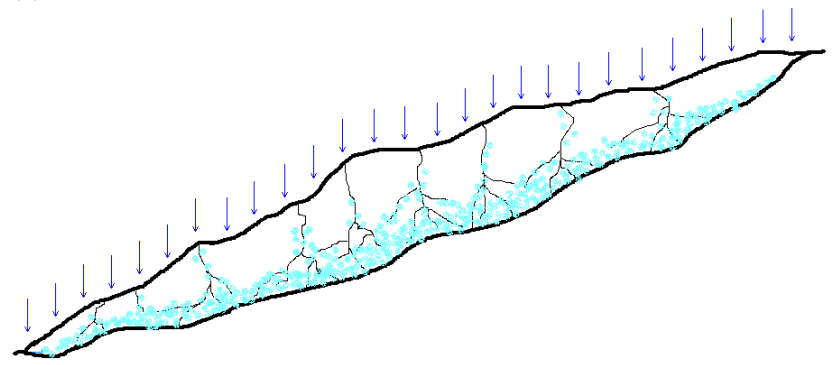

(b)

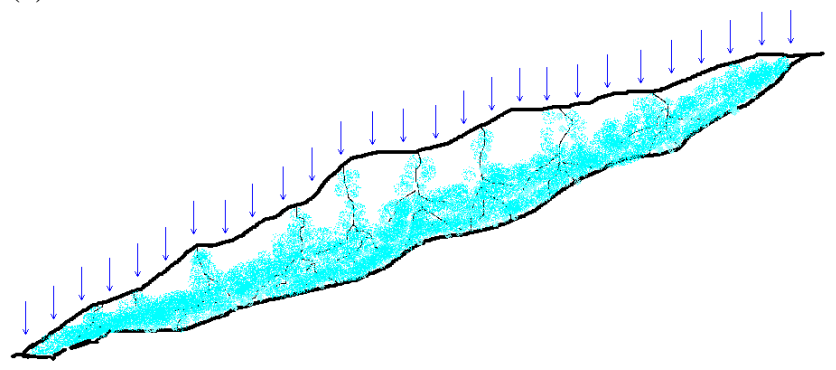

(c)

Fig. 3. Diagram of the slope: (a) infiltration from the zones around the macro-pores; (b) wide portions of soil become saturated; (c) the saturated portions of soil extend and become continuous, leading to the loss of partial saturation in most of the soil.

of a little sliding (Fig. 1A); if this stratum is very thick, then the collapse may become catastrophic due to the presence of a large amount of water in the soil mass (Fig. 1D).

\subsection{The mathematical model}

This section deals with the description of the simple mathematical model that translates the physical phenomenon described in the previous section. It is divided into five subsections: the first subsection concerns the definition of the equilibrium equations, which govern the limit equilibrium method; the second subsection describes the destabilising forces; the third subsection describes the simplified way of accounting for the contribution of partial saturation to the shear strength of the soil; in the fourth subsection the link 


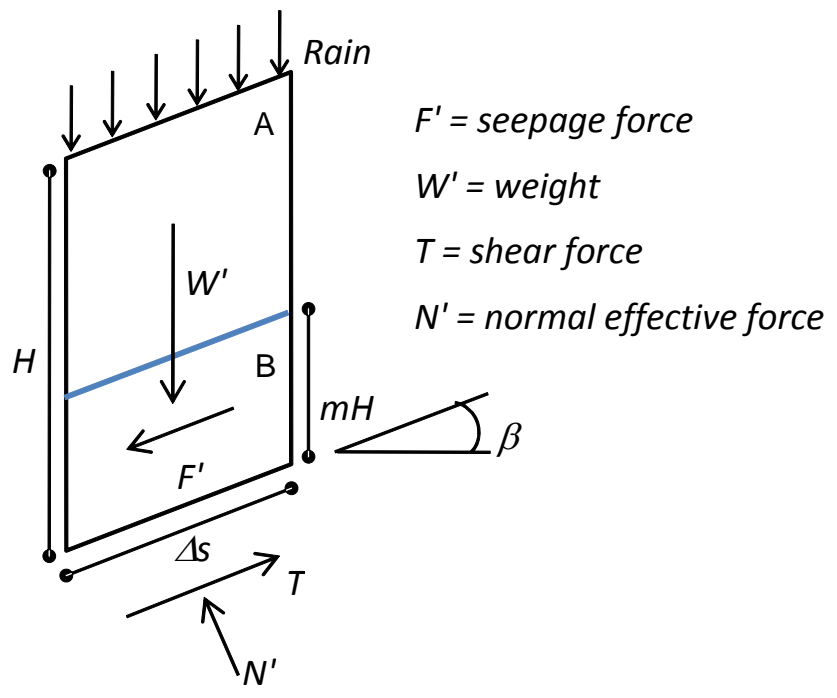

Fig. 4. Diagram of a single slice of an infinite slope with the acting forces.

between the rainfall amount and the condition of saturation in the soil is derived; the fifth subsection deals with the water down-flow and shows the final expression of $F_{S}$ (safety factor) in function of time.

\subsubsection{The equilibrium equations}

A model that translates into a mathematical form all the aspects of the physical phenomenon can be very complicated. Therefore, the simplification of the mathematical formulation is the only way to achieve the purpose of this work: the derivation of a method for alerting people against soil-slip occurrence.

Consequently, it has been chosen to model the most important physical aspects of the phenomenon, basing the formulation on simplified methods of analysis and taking into account only the principal aspects of the triggering mechanisms.

The hypotheses at the basis of the model are the following:

1. by considering the modest thickness of the soil involved in the movement, the problem is approached with the assumption of infinite slope;

2. from a hydraulic point of view, it is assumed that the permeability of the substratum is far inferior to that of the top-soil;

3. stability is guaranteed by the apparent cohesion, caused by the partial saturation of the soil;

4. the entire amount of rain infiltrates through the soil: run-off and evapo-transpiration are neglected (this is the worst condition);
5. it is assumed that the instant of collapse is characterised by the formation of a saturated uniform stratum of finite thickness at the contact with the sub-soil (part B in Fig. 4); this assumption translates the much more complex phenomenon of the formation of portions of saturated soil that enlarge until reaching the instability condition (described in Sect. 2.1); the thickness $(m H)$ of this saturated stratum is directly linked to the rainfall depth $(h)$;

6. all complex mechanisms that induce the water to leave from the top-soil are summarized by a simplified hypothesis, according to which $m H$ decreases following a negative exponential function, ruled by a $K_{T}$ factor that represents the global drainage capability of the slope.

All these assumptions can be translated into a simple mathematical formulation that is based on the use of the limit equilibrium method. This allows to derive a closed-form solution, easily applicable to wide territories, once they are divided into unitary cells in a rasterized GIS.

Figure 4 shows the geometrical characteristics of a slice of an infinite slope (which is inclined by an angle $\beta$ with respect to the horizontal), whose thickness is $H$ and whose length is $\Delta s$.

The stratum is composed of two soil portions: partially saturated soil (A), which is characterized by a degree of saturation $S_{r}$, and fully saturated soil (B), whose thickness is $m H$, where $m$ is a fractional parameter between 0 and 1 .

The safety factor $F_{S}$ is defined by the ratio between the stabilising actions $T_{s}$ and destabilising actions $T_{d}$.

$F_{S}=\frac{T_{S}}{T_{d}}$

The triggering of a soil slip is assumed to be associated with $F_{S}=1$.

\subsubsection{Remarks about $T_{d}$}

The expression of the destabilising force $T_{d}$ may be obtained by imposing the equilibrium on the translation along the direction parallel to the slope:

$T_{d}=W^{\prime} \cdot \sin \beta+F^{\prime}$

where $W^{\prime}$ is the submerged weight of the single element shown in Fig. 4 and $F^{\prime}$ is the seepage force, which arises in consequence to the water-flow parallel to the slope in the saturated layer.

The expression of $W^{\prime}$ thus appears:

$W^{\prime}=\cos \beta \cdot H \cdot \Delta s \cdot \gamma_{w}\left[m(n-1)+G_{S}(1-n)+n S_{r}(1-m)\right]$

where $n$ is the porosity, $G_{S}$ is the specific weight, $S_{r}$ is the degree of saturation of the soil and $\gamma_{w}$ is the unit weight of the water. Equation 3 has been derived under the hypothesis 
that the $\chi$ factor (Fredlund and Rahardjo, 1993) is equal to zero and this implies that the effective stress is equal to the total stress.

The seepage force $F^{\prime}$ is calculated through the following equation:

$F^{\prime}=\gamma_{w} \cdot \sin \beta \cdot \cos \beta \cdot m \cdot H \cdot \Delta s$

\subsubsection{Remarks about $T_{S}$}

The total stabilising action $T_{s}$ depends on the shear strength characteristics of the soil and may be obtained on the basis of the Mohr-Coulomb failure criteria:

$T_{s}=N^{\prime} \cdot \tan \phi^{\prime}+C^{\prime}$

The expression of $N^{\prime}$, which is linked to $W^{\prime}$, is:

$N^{\prime}=\cos ^{2} \beta \cdot H \cdot \Delta s \cdot \gamma_{w}\left[m(n-1)+G_{S}(1-n)+n S_{r}(1-m)\right]$

where the symbols refer to the quantities previously defined. The meaning of $C^{\prime}$ in Eq. (5) is specified as follows.

It is well known that Mohr-Coulomb failure criteria for saturated soils are defined by the following equation:

$\tau=\left(\sigma-u_{w}\right) \cdot \tan \phi^{\prime}+c^{\prime}$

where $c^{\prime}$ is the effective cohesion of soil and $\phi^{\prime}$ the shear strength angle.

For unsaturated soils, Fredlund and Rahardjo (1993) proposed the following equation:

$\tau=c^{\prime}+\left(\sigma_{n}-u_{a}\right) \cdot \tan \phi^{\prime}+\left(u_{a}-u_{w}\right) \cdot \tan \phi^{b}$

where $\left(\sigma_{n}-u_{a}\right)$ is the net normal stress state on the failure plane at failure, $u_{a}$ is the pore-air pressure on the failure plane at failure, $\left(u_{a}-u_{w}\right)$ is the matric suction and $\phi^{b}$ is the angle indicating the rate of increase in shear strength relative to the matric suction $\left(u_{a}-u_{w}\right)$.

The term $\left(u_{a}-u_{w}\right) \tan \phi^{b}$, which represents the contribution of the matric suction to the shear strength, does not depend on a normal applied stress and therefore can be considered similar to the contribution given by the effective cohesion $c^{\prime}$.

As reported by Fredlund et al. (1996), Peterson (1988) proposed the following equation:

$\tau=c^{\prime}+\left(\sigma_{n}-u_{a}\right) \cdot \tan \phi^{\prime}+c_{\psi}$

where $c_{\psi}$ represents the apparent cohesion related to the matric suction, which in turn, depends on the degree of saturation of the soil.

It can be shown that the shear strength of an unsaturated soil is a function of matric suction (Gan and Fredlund, 1996; Fredlund et al., 1996). When the soil is fully saturated the minimum shear strength corresponds to a value of zero matric suction. The shear strength increases until it reaches a peak and then decreases for higher values of matric suction.

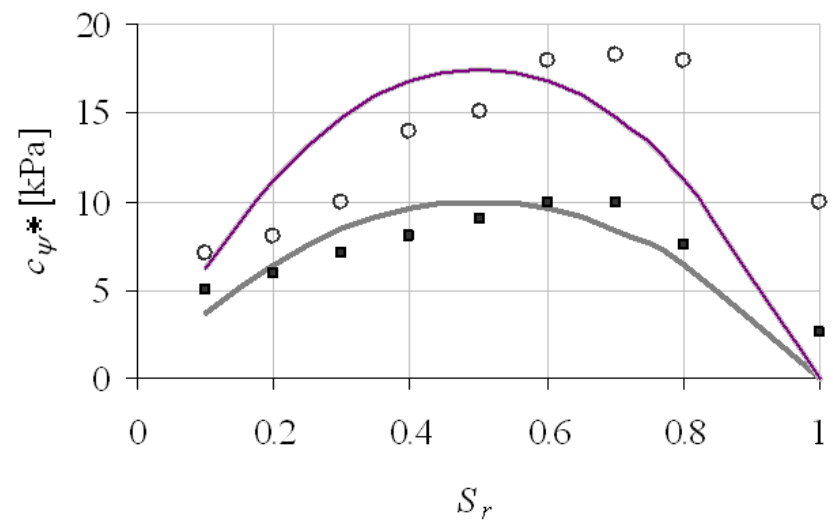

Fig. 5. Shear strength versus degree of saturation for two soil samples (modified from Fredlund et al., 1996).

It can be noticed that from a practical point of view the matric suction is quite complicated to determine, while the degree of saturation can be evaluated in a much simpler way. Therefore, for the model presented, it was preferable to express the shear strength as a function of the degree of saturation, due to the relationship between the water content, the degree of saturation and the matric suction. The contribution of matric suction to the shear strength at a particular stress state, which is considered as an increase of the cohesion of the soil, can be derived from the trend of the shear strength against suction, once the shear strength of the soil at zero suction (i.e. at a saturated condition) has been removed. On the basis of some experimental results obtained by Fredlund et al. (1996) for different kinds of soil, such as medium- and fine-grained sands, it has been possible to obtain the experimental points shown in Fig. 5. They represent a condition near to the real soil behaviour at low confining pressures, which are comparable with those present in the shallow part of the natural soil. The experimental $c_{\psi}-S_{r}$ trend can be fitted by a curve having a peak, whose value depends on the type of soil and corresponds to a degree of saturation approximately equal to 0.7 .

The experimental data in Fig. 5 can be reasonably approximated by curves having the following equation:

$c_{\psi}^{*}=A \cdot S_{r} \cdot\left(1-S_{r}\right)^{\lambda}$

where $S_{r}$ is the degree of saturation; $A$ is a parameter depending on the kind of soil and is linked to the peak shear stress at failure; $\lambda$ is a numerical parameter which allows to translate the peak of the curve along the abscissa axis.

The values of parameters $\lambda$ and $A$ have been identified for the most common kind of soil on the Italian territory and are shown in Table 1. They were obtained from a number of experimental tests (Mari, 2000; Montrasio and Valentino, 2003, 2007). 
Table 1. Parameters $\lambda$ and $A$ for different types of soil.

\begin{tabular}{lrr}
\hline SOIL & $\lambda$ & $A$ \\
\hline Soft clay (OCR=1) & 0.4 & 100 \\
Medium clay (OCR $>1)$ & 0.4 & 100 \\
Stiff clay (OCR $\gg 1)$ & 0.4 & 100 \\
Clayey mud & 0.4 & 80 \\
Mud & 0.4 & 80 \\
Sandy mud & 0.4 & 80 \\
Loose sand & 0.4 & 40 \\
Medium sand & 0.4 & 40 \\
Dense sand & 0.4 & 40 \\
\hline
\end{tabular}

To translate the complex physical phenomenon described in Sect. 2.1 by using the simplified limit equilibrium method, it is assumed that the stability of the slope is guaranteed (even if $m \neq 0$ and until $m$ reaches a critical value) due to the shear strength contribution provided by the unsaturated part of the soil. The soil slice is composed of two different layers: an unsaturated one (A in Fig. 4, where $c_{\psi}^{*} \neq 0$ ) and a saturated one (B in Fig. 4, where $c_{\psi}^{*}=0$ ). They can be homogenized in a single stratum having an apparent cohesion as a function of the thickness of the saturated stratum. From experimental results on stratified soils of different characteristic values of $c_{\psi}^{*}$ and of different thickness (Silva, 2000) the following equation, which expresses the apparent cohesion homogenized in the whole soil slice, has been obtained:

$c_{\psi}=c_{\psi}^{*} \cdot(1-m)^{\alpha}$

where $\alpha$ is a parameter that gives a non-linear trend to the curve representing the function. The best value for $\alpha$ obtained from the tests performed is $\alpha=3.4$.

Then the total cohesion intercept results as follows:

$C^{\prime}=\left[c^{\prime}+c_{\psi}\right] \cdot \Delta s=\left[c^{\prime}+A \cdot S_{r} \cdot\left(1-S_{r}\right)^{\lambda} \cdot(1-m)^{\alpha}\right] \cdot \Delta s$

2.2.4 The link between the parameter $m$ and the rainfall depth

The parameter $m$ represents the dimensionless thickness of the saturated part of the layer and, thus, is a fractional parameter between 0 and 1 . It can be constant or variable in time and is correlated to the volume of water $V_{w}$ required to saturate a slice of soil, which is initially characterised by a degree of saturation $S_{r}<1$. Considering a slice of soil, whose slope is $\beta$, thickness $m H$, length $\Delta s$ and unit width (1) (see Fig. 4) it is possible to obtain the relationship between parameter $m$ and water volume $V_{w}$ that saturates the soil. It is given by:

$V_{w}=m \cdot H \cdot n \cdot\left(1-S_{r}\right) \cdot \Delta s \cdot 1$ so

$m=\frac{V_{w}}{n \cdot H \cdot\left(1-S_{r}\right) \cdot \Delta s \cdot 1}$

where $n$ and $S_{r}$ are respectively the porosity and the degree of saturation of the soil. $V_{w}$ is the volume of water related to $\Delta s \cdot 1$ sized surface. Therefore, the ratio $\frac{V_{w}}{\Delta s \cdot 1}$ that is present in Eq. (14) represents the water depth $H_{w}$, which is able to saturate the lower part of the slice. $H_{w}$, in turn, can be considered equal to the rainfall depth $(h)$, because it has been assumed that an increment of water depth $\Delta H_{w}$, caused by a rainfall, crosses the upper unsaturated part of the layer (A in Fig. 4) without modifying its degree of saturation, instantaneously reaching the impermeable layer and provoking an increment of $m(\Delta m)$. Equation (14) then becomes as follows:

$m=\frac{h}{n \cdot H \cdot\left(1-S_{r}\right)}$

Since it is necessary to consider time-varying rainfalls, Equation (15) is written in an incremental form, assuming $n, H$ and $S_{r}$ are constant in time, as follows:

$\dot{m}=\frac{\dot{h}}{n \cdot H \cdot\left(1-S_{r}\right)}$

\subsubsection{The water down-flow condition}

The integration of Eq. (16) leads to write $m(t)$ as function of $h(t)$ in case of the boundary conditions of the problem are such that each increment of rainfall depth $(h)$ gives rise to a progressive growth of parameter $m$. From a physical point of view, this fact implies that the soil stratum behaves like a reservoir storing an ever increasing amount of water. Evidently, this condition is not realistic. In consequence of different forms of down-flow, such as the seepage through the substratum or through other preferential ways, like pipes or soil cracks, and other phenomena like evapo-transpiration, a progressive decrease of the water amount in the layer occurs leading to a reduction of $m$.

Taking into account all these complex mechanisms, it was chosen to express the decrease of $m$ through a simple exponential negative law, derived by the integration of the equation representing the water balance of a finite portion of a slope of finite length $L$, in which only a flow parallel to the slope is considered.

The water balance can be written as an equation of continuity and results as follows:

$K_{T} \cdot \sin \beta \cdot m \cdot H \cdot \cos \beta \cdot \Delta t=n \cdot \Delta m \cdot H \cdot \cos \beta \cdot L \cdot\left(1-S_{r}\right)$

where $t$ is the time, while all other symbols keep the same significance as in the previous sections.

By integrating the left- and the right-hand members of Eq. (17), $m$ can be expressed as the following function of time:

$m(t)=m_{0} \cdot e^{-K_{T} \cdot \frac{\sin \beta}{n \cdot L \cdot\left(1-S_{r}\right)} \cdot\left(t-t_{0}\right)}$ 
where $m_{o}$ is the value of $m$ corresponding to the time instant $t=t_{o}, L$ is kept equal to 1 and $K_{T}$ assumes the significance of a global drainage capability, which is due not only to the intrinsic soil permeability, but also to the presence of a lot of preferential down-flow ways, as previously indicated.

If instead of representing an instantaneous variation of $m$, $m_{o}$ was in turn a function of time, then the function $m_{o}(t)$ could be discretized and the function $m(t)$ could be considered as the sum of a succession of terms $m_{o i}$, corresponding to different instants of time $t_{o i}$. In short, under the assumption that all the parameters remain constant with time, Equation (18) is transformed into the summation:

$m(t)=\sum_{i} m_{0 i} \cdot e^{-K_{T} \cdot \frac{\sin \beta}{n \cdot\left(1-S_{r}\right)} \cdot\left(t-t_{0 i}\right)}$

with $m_{o i}$ being the variation of $m$ at the instant of time $t_{o i}$.

The parameter $m_{o i}$ can be correlated through Eq. (15) to the rainfall depth $h\left(t_{o i}\right)$, relative to the time instant $t_{o i}$, which can be the cumulated daily or hourly rainfall, if $t_{o i}$ is respectively a day or an hour:

$m_{0 i}=\frac{h\left(t_{0 i}\right)}{n \cdot H \cdot\left(1-S_{r}\right)}$

In the term:

$e^{-K_{T} \cdot \frac{\sin \beta}{n \cdot\left(1-S_{r}\right)} \cdot\left(t-t_{0 i}\right)}$

the negative exponent represents a sort of damping coefficient that intervenes to reduce the term $m_{o i}$ starting from the instant $t_{o i}$.

By substituting Eq. (20) into Eq. (19), one can derive the following expression for $m(t)$ :

$m(t)=\sum_{i} e^{-K_{T} \cdot \frac{\sin \beta}{n \cdot\left(1-S_{r}\right)} \cdot\left(t-t_{0 i}\right)} \cdot \frac{h\left(t_{0 i}\right)}{n \cdot H \cdot\left(1-S_{r}\right)}$

The safety factor that has been defined through Eq. (1) results as follows:

$F_{s}=\frac{\cot \beta \cdot \tan \phi^{\prime} \cdot\left[\Gamma+m \cdot\left(n_{w}-1\right)\right]+C^{\prime} \cdot \Omega}{\Gamma+m \cdot n_{w}}$

where

$\Gamma=G_{s} \cdot(1-n)+n \cdot S_{r}$

$n_{w}=n \cdot\left(1-S_{r}\right)$

$\Omega=\frac{2}{\sin 2 \beta \cdot H \cdot \gamma_{w}}$

In Eq. (23) parameter $m$, which changes in time, is calculated by using Eq. (22) at each time-step.

By considering the previously explained equations, the safety factor results as a function of the geometry (slope angle $\beta$, thickness of the soil layer $H$ ), the soil properties (porosity $n$, degree of saturation $S_{r}$, specific gravity $G_{s}$ ), the shear strength parameters (effective cohesion $c^{\prime}$, friction angle $\phi^{\prime}$ ) and the unit weight of water $\gamma_{w}$.
Table 2. The four case studies considered.

\begin{tabular}{llrl}
\hline $\begin{array}{l}\text { Sample } \\
\text { sites }\end{array}$ & Province & $\begin{array}{r}\text { Date of the } \\
\text { soil slip } \\
\text { occurrence }\end{array}$ & $\begin{array}{l}\text { Rain } \\
\text { gauges }\end{array}$ \\
\hline $\begin{array}{l}\text { Polinago } \\
\text { Palagano }\end{array}$ & Modena & 8 Nov 2003 & Polinago \\
Neviano & & 10 Apr 2005 & $\begin{array}{l}\text { Polinago } \\
\text { Neviano } \\
\text { Arduini }\end{array}$ \\
Salsomaggiore & Parma & 5 Oct 2005 & Arduini \\
6 Oct 2005 & Salsomaggiore \\
\hline
\end{tabular}

It is worth noting that, while the slope geometric features and physical soil characteristics can be reasonably considered unchangeable for a certain slope, the degree of saturation $\left(S_{r}\right)$ and the thickness of the saturated layer $(m H)$ change in consequence of weather conditions and rainfalls, and the shear strength parameters, in turn, are deeply influenced by the degree of saturation. The latter can be assumed time-varying in a range between 0.6 (Summer) and 0.9 (Winter) according to rainfall conditions.

\section{Application of the model to some rainfall-induced landslide movements in the Emilia Romagna Apen- nines (Northern Italy)}

The Emilia Romagna Region is an area notably subjected to landslide phenomena, which have become particularly frequent in recent years. Most of the landslides which have occurred in this region involved superficial soil portions of hilly areas and caused considerable damage to structures and infrastructures. In particular, a lot of shallow landslide phenomena, of the typology of soil slip, have occurred in the provinces of Modena and Parma in consequence of either severe storms or prolonged periods of light rainfalls. To conduct an analysis on the phenomenon by using the previously explained simplified model, four sample sites were taken into consideration with the dates of soil slip occurrence being known: Polinago (8 November 2003); Palagano (10 April 2004); Neviano Arduini (5 October 2005); Salsomaggiore Terme (6 October 2005) (see Table 2). The main purpose of the analysis was the validation of the simplified analytical model referred to the sites under examination.

\subsection{Choice of the model parameters}

The geometrical parameters, such as the inclination $(\beta)$ and the thickness of the unstable layer $(H)$, were determined through the relief of the geometry of each single slope subject to instability. The soils involved in the phenomenon were classified on the basis of laboratory tests on the samples collected, by determining their specific weight $\left(G_{s}\right)$, 
Table 3. Geometric and geotechnical parameters relative to the four sample sites.

\begin{tabular}{lllllllll}
\hline Site & $\beta\left[^{\circ}\right]$ & $H[\mathrm{~m}]$ & $n$ & $G_{s}$ & $\phi^{\prime}\left[{ }^{\circ}\right]$ & $c^{\prime}[\mathrm{kPa}]$ & $K_{T}\left[s^{-1}\right]$ & Type of soil \\
\hline Polinago & 25 & 2 & 0.48 & 2.70 & 33 & 0 & $3.0 \cdot 10^{-7}$ & Sandy silt \\
Palagano & 30 & 2 & 0.48 & 2.70 & 33 & 0 & $1.0 \cdot 10^{-6}$ & Sandy silt \\
Neviano Arduini & 30 & 1.80 & 0.4 & 2.55 & 25 & 0 & $2.5 \cdot 10^{-7}$ & Clayey silt \\
Salsomaggiore & 41 & 2.25 & 0.4 & 2.00 & 26 & 0 & $1.8 \cdot 10^{-7}$ & Clayey silt \\
\hline
\end{tabular}

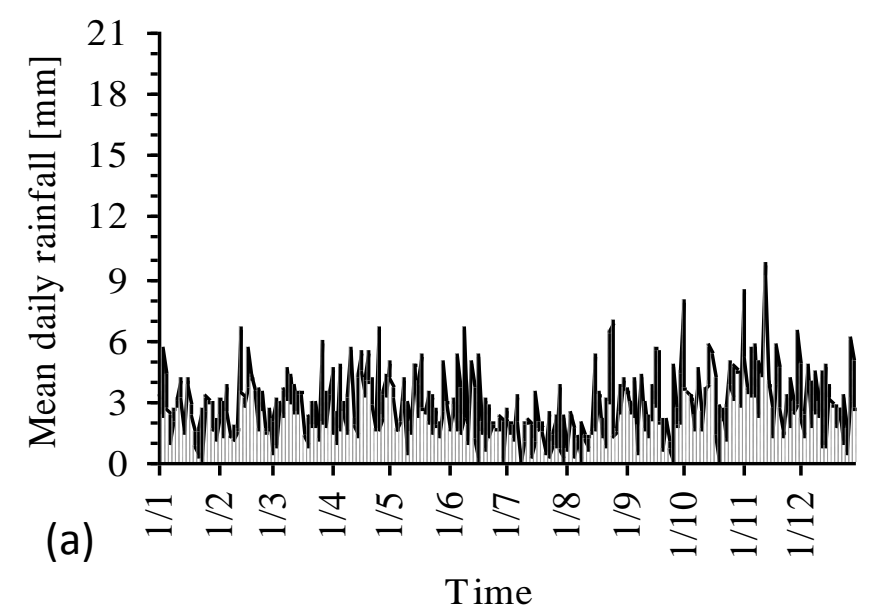

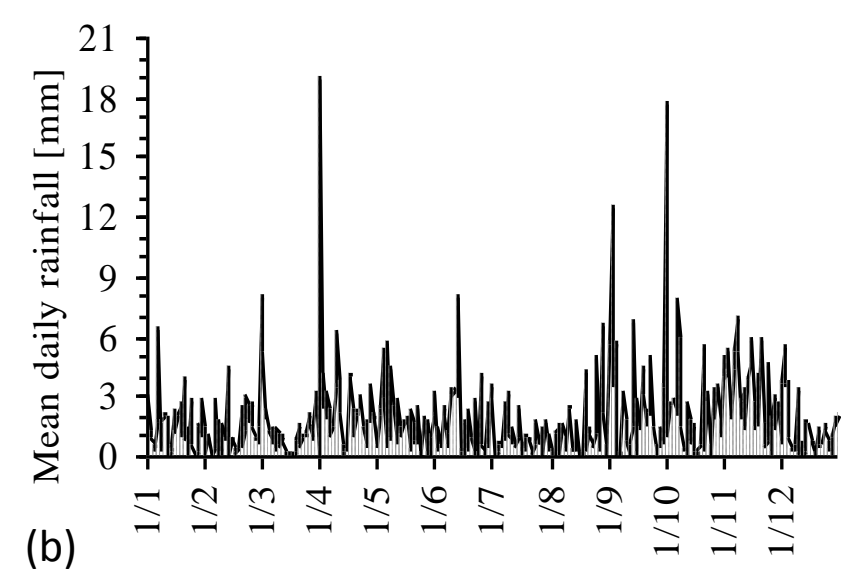

Time

Fig. 6. Mean daily trend on an annual basis of rainfalls at Neviano Arduini in two different periods of observation: (a) 19511980 and (b) 1980-2006 (Data from ARPA-SIM Emilia Romagna).

granulometry and Atterberg Limits. Other soil characteristics, such as the status and strength parameters $\left(n, \phi^{\prime}, c^{\prime}\right)$, were not determined experimentally, instead mean values reported in classic geotechnical literature for the same type of soils have been assumed. The drainage capability $\left(K_{T}\right)$ for every site under consideration is the only parameter that has been adjusted through a procedure of back analysis. The input data for the model are shown in Table 3.

\subsection{Analysis of rainfalls}

A study was also performed on the pluviometric data recorded in stations close to the four localities. As an example, the rainfall data of Neviano Arduini rain gauge, available from 1951 to 2006, have been elaborated in such a way as to analyse the trend of the average daily rainfall, with reference to the calendar year (Fig. 6). From these trends one can deduce how, over the years, rainfalls underwent certain modifications. In a more recent period (1980-2006) the climate seems to be characterised by a fewer number of rainy days but with heavier storms with respect to the averages recorded in the 1951-1980 period.

\subsection{Results}

As already outlined in the previous sections, the model set up for the description of the triggering mechanism of soil slips was conceived as a simplified method of analysis.

The results obtained through the application of the simplified model to the four sample sites, on the basis of the geotechnical and pluviometric data relative to each event considered, make it possible to obtain the trend of the safety factor in time. Figure 7 shows the trend in time of the safety factor as a function of daily rainfall depth for each case study. Referring to Sect. 2.2.1, the triggering of the soil slip is represented by the condition $F_{s}=1$ (dashed line in Fig. 7). It can be seen how the model accurately estimates the drastic reduction of the safety factor down to the condition $F_{s}=1$ for all sample sites, in agreement with the dates of the event occurrence, which are reported in Table 2 . The rainfall amount, in terms of daily water depth, was considered as input data relative to a 12-month period around the date corresponding to each event. 

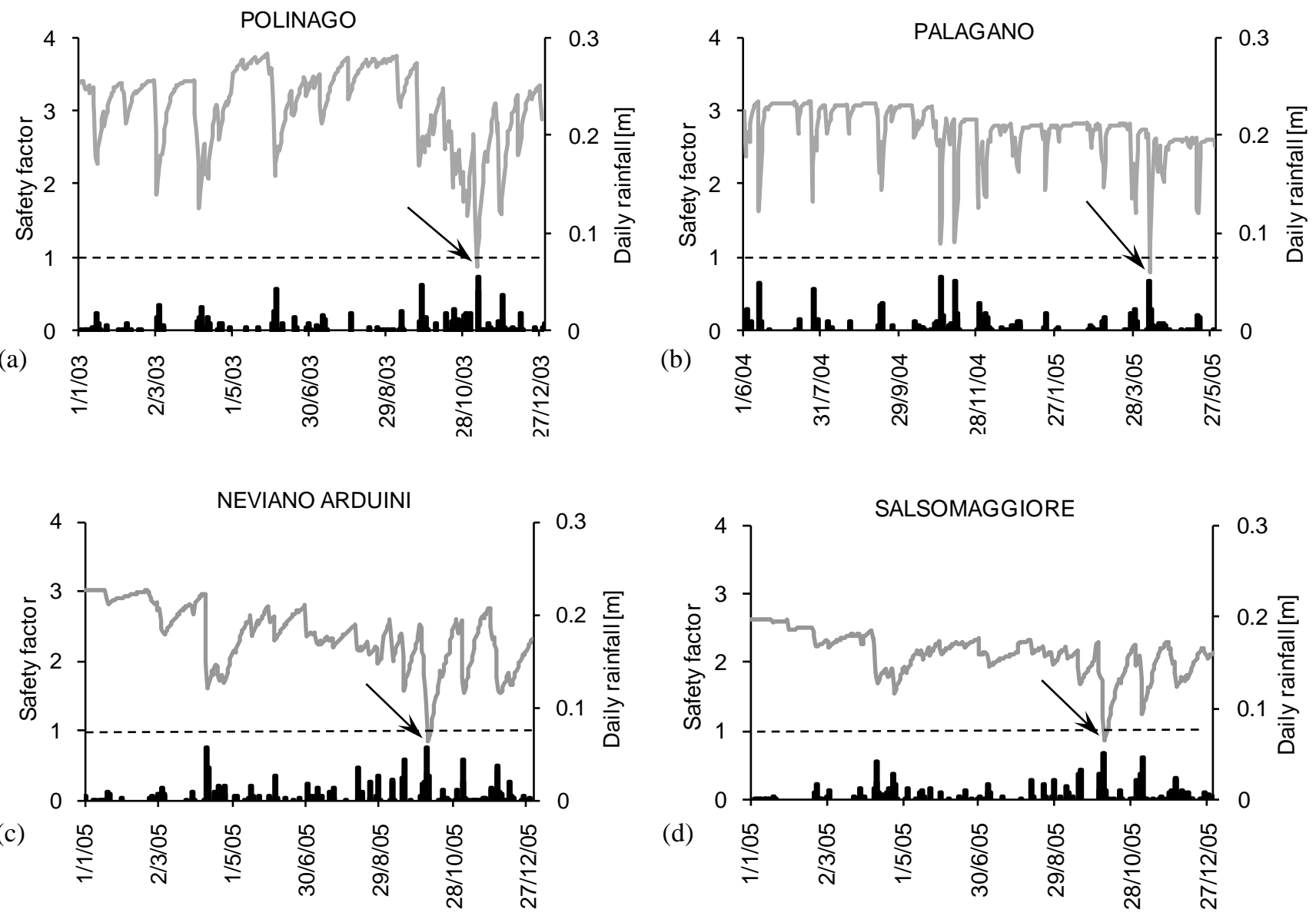

Fig. 7. Measured daily rainfall and trend of the safety factor as a function of time, on an annual basis, in the localities of (a) Polinago, (b) Palagano, (c) Neviano Arduini, (d) Salsomaggiore.

It can be observed that, notwithstanding the model seems to be affected by rainfalls, during all the other periods the safety factor maintains its value higher than one (i.e. stability condition) in agreement with the observed behaviour of the slopes.

\section{Concluding remarks}

A simplified physically based stability model for the assessment of the safety factor of slopes susceptible to rainfallinduced shallow landslides has been presented.

This model can describe the most important factors influencing the beginning of the slope movement without the introduction of too many parameters. On the basis of the limit equilibrium method, the model defines the safety factor of a slope taking into account the slope geometric features, the geotechnical characteristics and the shear strength of the soil, both in saturated and unsaturated conditions, the drainage capability of the slope, and the way of rainfall infiltration. The model, which allows a direct correlation between the safety factor and rainfall intensities, has been used to verify its capability in foreseeing the occurrence of the phenomenon in four recent cases in the Emilia Romagna Apennines (Northern Italy), on the basis of soil mechanical and hydraulic characteristics, geometrical configuration of the slopes and timevarying rainfall conditions. It has been shown how, for each case study, the model accurately estimates the variation of the safety factor in time and reduces the value of the safety factor to equal $F_{S}=1$ (i.e. the instability condition) in correspondence to the dates of occurrence of the real events.

Acknowledgements. The Authors acknowledge the support for this work from the Italian MIUR (COFIN 2001) and from EC Funding (Spinner Project 2005). The helpful comments by two anonymous reviewers are appreciated.

Edited by: F. Catani

Reviewed by: two anonymous referees 


\section{References}

Alonso, E., Gens, A., and Lloret, A.: Effect of rain infiltration on the stability of slopes, in: Unsaturated Soils, Proc. 1st Int. Conf. On Unsaturated Soils, Balkema, Rotterdam, 241-249, 1995.

Bandis, S. C.: Geotechnical considersations - numerical modelling, in: Meteorological Events and Natural Disasters, Casale and Margottini, 55-73, 1996.

Bouma, J. and Dekker, L. W.: A case of study on infiltration into dry clay soil. Morphological observations, Geoderma, 20, 27-40, 1978.

Bouma, J.: Comment on "Micro, meso and macroporosity of Soil", Soil Sci. Soc. Am. J., 45(6), 1244-1245, 1981.

Bouma, J.: Influence of soil macroporosity on environmental quality, Adv. Agron., 46, 1-37, 1991.

Campbell, R. H.: Soil Slips, Debris Flows and Rainstorms in the Santa monica Mountains and Vicinity, Southern California, Geol. Surv. Prof. Paper 851, 51 pp., 1975.

Campus, S., Forlati, F., Susella, G., and Tamberlani, F.: Frane per mobilizzazione delle coperture detritiche, in: Eventi alluvionali in Piemonte, Regione Piemonte, Torino, 266-287, 1998.

Cardinali, M., Galli, M., Guzzetti, F., Ardizzone, F., Reichenbach, P., and Bartoccini, P.: Rainfall induced landslides in December 2004 in south-western Umbria, central Italy: types, extent, damage and risk assessment, Nat. Hazards Earth Syst. Sci., 6, 237260, 2006, http://www.nat-hazards-earth-syst-sci.net/6/237/2006/.

Cascini, L., Guida, D., Romanzi, G., Nocera, N., and Sorbino, G.: A preliminary model for the landslides of May 1998 in Campania Region, in: Proc. of 2nd Int. Symp. on the Geotechnics of Hard Soils-Soft Rocks, edited by: Evangelista, A. and Picarelli, L., Balkema, Rotterdam, 1623-1649, 2000.

Cascini, L., Sorbino, G., and Cuomo, S.: Modelling of flowslide triggering in pyroclastic soil, in: Proc. of Int. Conf. on Fast Slope Movements - Prediction and prevention for risk mitigation, edited by: Picarelli, L., Patron Ed., Bologna, 93-100, 2003.

Cascini, L., Cuomo, S., and Sorbino, G.: Flow-like mass movements in pyroclastic soils: remarks on the modelling of triggering mechanisms, Italian Geotechnical Journal, 4, 11-31, 2005.

Clarizia, M., Gullà, G., and Sorbino, G.: Sui meccanismi di innesco dei soil slip, Proc. Int. Conf. on "La prevenzione delle catastrofi idrogeologiche: il contributo della ricerca scientifica", Alba, Vol. I, 1996.

Delmonaco, G., Leoni, G., Margottini, C., Puglisi, C., and Spizzichino, D.: Large scale debris-flow hazard assessment: a geotechnical approach and GIS modelling, Nat. Hazards Earth Syst. Sci., 3, 443-455, 2003,

http://www.nat-hazards-earth-syst-sci.net/3/443/2003/.

Ellen, S. D. and Wieczorek, G. F.: Landslides, Floods and Marine Effects of the Storm of January 3-5 1982, in the San Francisco bay Region, California, US Geological Survey Professional Paper 1434, 310 pp., 1988.

Emilia Romagna Region, Servizio Geologico Sismico e dei Suoli, Servizio Provinciale Difesa del Suolo di Reggio Emilia, Servizio Protezione Civile, Servizio Idro-Meteo regionale, CNR-GNDCI: Carta della pericolosità relativa da frana, ai fini di protezione civile, 2002.

Fredlund, D. G. and Rahardjo, H.: Soil Mechanics for unsaturated soils, John Wiley \& Sons, 1993.

Fredlund, D. G., Xing, A., Fredlund, M. D., and Barbour, S. L.:
The relationship of the unsaturated soil shear strength to the soil-water characteristic curve, Can. Geotech. J., 33-3, 440-448, 1996.

Gan, J. K. N. and Fredlund, D. G.: Shear strength characteristics of two saprolitic soils, Can. Geotech. J., 33, 595-609, 1996.

Govi, M. and Mortara, G.: I dissesti prodotti dal nubifragio del 10 luglio 1972 nella Bassa Valle Seriana, Bollettino Associazione Mineraria Subalpina, Anno XVIII, 87-118, 1981.

Govi, M. and Sorzana, P. F.: Landslide susceptibility as a function of critical rainfall amount in Piedmont basin (North-Western Italy), Studia Geomorphologica Carpatho-Balcanica, 14, 43-61, 1980.

Govi, M., Mortara, G., and Sorzana, P. F.: Eventi idrologici e frane, in: Geologia Applicata e Idrogeologia, Vol. XX, Part 2, 358-375, 1985.

Haefeli, R.: The stability of slopes acted upon by parallel seepage, Proc. 2nd Int. Conf. On Soil Mech. and Found. Engrg., 1, 57-62, 1948.

Hodge, R. A. and Freeze, R. A.: Groundwater flow systems and slope stability, Can. Geotech. J., 14(4), 466-476, 1977.

Iverson, R. M.: Landslide triggering by rain infiltration, Water Resour. Res., 36, 1897-1910, 2000.

Iverson, R. M. and Major, J. J.: Rainfall, ground-water flow, and seasonal movement at Minor Kreek landslide, northwest California: physical interpretation of empirical relations, Geol. Soc. Am. Bull., 99, 579-594, 1987.

Kesseli, J. E.: Disintegrating soil slips of the Coast Ranges of Central California, J. Geol. Bull., 51(5), 342-352, 1943.

Mari, M.: Un metodo per la valutazione del grado di stabilità di pendii a rischio di scivolamenti superficiali, Degree Thesis, University of Parma, 2000.

Montgomery, D. R. and Dietrich, W. E.: A physically based model for the topographic control on shallow landsliding, Water Resour. Res., 30(4), 1153-1171, 1994.

Montrasio, L.: Stability analysis of soil slip, in: Proc. of Int. Conf. "Risk 2000", edited by: Brebbia, C. A., Wit Press, Southampton, 357-366, 2000.

Montrasio, L., Re, F., and Valentino, R.: An approach to measure soil slip risk, in: Proc. of 3rd Int. Conf. On Comp. Simulation in Risk Analysis and Hazard Mitigation "Risk Analysis III", edited by: Brebbia, C. A., Wit Press, Southampton, 729-740, 2002.

Montrasio, L. and Valentino, R.: Experimental analysis on factors triggering soil slip, in: Proc. of Int. Conf. on Fast Slope Movements Prediction and prevention for risk mitigation, edited by: Picarelli, L., Patron Ed., Bologna, 371-378, 2003.

Montrasio, L. and Valentino, R.: Experimental analysis and modelling of shallow landslides, Landslides, 4, 291-296, 2007.

Olivares, L.: Static liquefaction: an hypothesis for explaining transition from slide to flow in pyroclastic soils, in: Proc. of Conf. on Transition from slide to flow - mechanisms and remedial measure, Karadeniz Technical University, Trabzon, 25-26 August 2001.

Olivares, L. and Picarelli, L.: Susceptibility of loose pyroclastic soils to static liquefaction: some preliminary data, in: Proc. of Int. Conf. on Landslides - Causes, Impacts and Countermeasures, Davos, 75-85, 2001.

Rulon, J. J. and Freeze, R. A.: Multiple seepage faces on layered slopes and their implications for slope stability analysis, Can. Geotech. J., 22, 347-356, 1985. 
Salciarini, D., Godt, J. W., Savage, W. Z., Conversini, P., Baum, R. L., and Michael, J. A.: Modeling regional initiation of rainfallinduced shallow landslides in the eastern Umbria Region of central Italy, Landslides, 3, 181-194, 2006.

Sidle, R. C. and Swanston, D. N.: Analysis of a small debris slide in coastal Alaska, Can. Geotech. J., 19(2), 167-174, 1982.

Silva, D.: Analisi sperimentale del comportamento di terreni stratificati in pendio, Degree Thesis, University of Parma, 2000.

Sutera Sardo, P., Beretta, G. P., De Luca, D. A., and Masciocco, L.: Frane superficiali innescatesi nei dintorni di Ceva $(\mathrm{Cn})$ in conseguenza dell'evento meteorologico del novembre 1994, Proc. Int. Conf. on "La prevenzione delle catastrofi idrogeologiche: il contributo della ricerca scientifica", Alba, Vol. I, 1996.
Valentino, R.: Analisi di movimenti franosi superficiali della coltre detritica, Degree Thesis, University of Parma, 1999.

Versace, P., Sirangelo, B., and Capparelli, G.: A hydrological model to assess the activation probability of landslides triggered by rainfall, in: Proc. 1st Italian-Russian Workshop "New Trends in Hydrology", Rende(CS), Italy, 2002.

Zahn, T. L. T., Ng, C. W. W., and Fredlund, D. G.: Field study of rainfall infiltration into a grassed unsaturated expansive soil slope, Can. Geotech. J., 44, 392-408, 2007. 